Article Type: Commentary

NOTES

Ref 1: [add details at production]

COMMENTARY

$\mathrm{JP}$

12 March 2017

Ms. No. 16/1455-Commentary A

\title{
Hair-follicle dermal papilla and sheath fibroblasts provide a supportive microenvironment for human skin regeneration
}

DOI: $x x$ [add details at production]

Linked Article: Higgins et al. Br J Dermatol 2017; xxx:xxx-Xxx. [add details at production]

P. Kaur

School of Biomedical Sciences, Curtin University, Perth, Australia

Correspondence

E-mail: pritinder.kaur@curtin.edu.au

\section{Funding sources}

No external funding.

\section{Conflicts of interest}

None to declare.

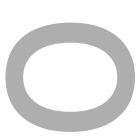

This issue of $B J D$ includes a paper from Higgins et al., ${ }^{1}$ reporting an important advance in skin regeneration, demonstrating that human hair-follicle-associated dermal cell populations can provide the necessary signals for complete human epidermal tissue regeneration. These data are valuable given that replacing extensive skin tissue loss resulting from injuries, burns or genetic defects remains a challenge, particularly in the face of restrictions on the use of animal products imposed by regulatory agencies. The most widely used technique for skin replacement is autografting from another body site an option that is not always available to patients with extensive skin loss - and also one

This is the author manuscript accepted for publication and has undergone full peer review but has not been through the copyediting, typesetting, pagination and proofreading process, which may lead to differences between this version and the Version of Record. Please cite this article as doi: $10.1111 /$ bjd.15474 
that does not yield an aesthetically pleasing outcome. For patients where skin loss encompasses much of the body surface, the patient's remaining healthy skin is harvested, and the keratinocytes isolated from it for expansion in culture, prior to autografting, as epithelial sheets.

The best technique for clonal human keratinocyte expansion remains co-culture with an irradiated or mitomycin C-treated feeder layer of the J2 strain of Swiss 3T3s - a 'fibroblastic' cell line derived from mouse embryos - developed by Rheinwald and Green. ${ }^{2}$ This technique and subsequent work in 3D organotypic models provides strong evidence that mesenchymal cell-derived secreted factors are critical for skin regeneration. ${ }^{3,4} \mathrm{~A}$ thorough evaluation of alternatives to murine Swiss 3T3s in both 2D monolayer cultures and 3D organotypic cultures has not been undertaken. However, it has been demonstrated that human skin-derived dermal fibroblasts, ${ }^{5,6}$ particularly those originating from the papillary dermis located adjacent to the interfollicular epidermis, were better at promoting epidermal regeneration than those from the deeper reticular dermis. ${ }^{7}$ Dermal pericytes ${ }^{8}$ and adipose-derived mesenchymal stem cells ${ }^{9}$ can also support skin regeneration in organotypic cultures. Notably, dermal pericytes were capable of conferring improved skin regenerative capacity on interfollicular keratinocytes that were already committed to differentiate, when combined with dermal fibroblasts. ${ }^{8}$

The team of Jahoda and colleagues previously reported that hair follicle-associated mesenchymal cells, specifically the hair-inductive dermal papilla fibroblasts and dermal sheath fibroblasts, promote greater keratinocyte colony-forming efficiency than dermal fibroblasts in $2 \mathrm{D}$ culture. ${ }^{10}$ In the current study, this group ${ }^{1}$ advances this knowledge further, demonstrating that dermal papilla and dermal sheath fibroblasts - normally associated with hair follicle regeneration - can also support interfollicular skin regeneration in organotypic cultures. Moreover, the full programme of epithelial proliferation and differentiation was observed as judged by the presence of a $\mathrm{Ki} 67^{+} / \mathrm{K}^{+}$ basal layer and suprabasal expression of the keratinocyte differentiation markers K1 and loricrin. Further, the quality of the regenerated interfollicular epithelium obtained with these heterotypic fibroblasts was substantially improved with respect to basement membrane assembly compared with the results obtained with homotypic interfollicular dermal fibroblasts. Consistent with this, Cho et al. have reported improved $\alpha 6$ integrin expression in organotypic cultures containing dermal sheath vs. interfollicular skin-derived dermal fibroblasts. ${ }^{11}$ Importantly, Higgins et al. ${ }^{1}$ provide conclusive evidence that hair follicle-associated fibroblasts could be utilized in clinical applications to generate 3D skin reconstructs for transplantation without compromising skin integrity. 


\section{References}

1 Higgins CA, Roger M, Hill R et al. Multifaceted role of hair follicle dermal cells in bioengineered skins. Br J Dermatol 2017 (in press). [add details at production]

2 Rheinwald JG, Green H. Serial cultivation of strains of human epidermal keratinocytes: the formation of keratinizing colonies from single cells. Cell 1975; 6:331-43.

3 Asselineau D, Bernard BA, Bailly C et al. Human epidermis reconstructed by culture: is it 'normal'? J Invest Dermatol 1986; 86:181-6.

4 Bell E, Ehrlich HP, Buttle DJ, Nakatsuji T. Living tissue formed in vitro and accepted as skin-equivalent tissue of full thickness. Science 1981; 211:1052-4.

5 el-Ghalbzouri A, Gibbs S, Lamme E et al. Effect of fibroblasts on epidermal regeneration. Br J Dermatol 2002; 147:230-43.

6 Boehnke K, Mirancea N, Pavesio A et al. Effects of fibroblasts and microenvironment on epidermal regeneration and tissue function in long-term skin equivalents. Eur J Cell Biol 2007; 86:731-46.

7 Sorrell JM, Baber MA, Caplan AI. Site-matched papillary and reticular human dermal fibroblasts differ in their release of specific growth factors/cytokines and in their interaction with keratinocytes. J Cell Physiol 2004; 200:134-45.

8 Paquet-Fifield S, Schluter H, Li A et al. A role for pericytes as microenvironmental regulators of human skin tissue regeneration. J Clin Invest 2009; 119:2795-806.

9 Huh C, Kim S, Cho H et al. Effects of mesenchymal stem cells in the reconstruction of skin equivalents. J Dermatol Sci 2007; 46:217-20.

10 Hill RP, Gardner A, Crawford HC et al. Human hair follicle dermal sheath and papilla cells support keratinocyte growth in monolayer coculture. Exp Dermatol 2013; 22:236-8. 11 Cho HJ, Bae IH, Chung HJ et al. Effects of hair follicle dermal sheath cells in the reconstruction of skin equivalents. J Dermatol Sci 2004; 35:74-7.

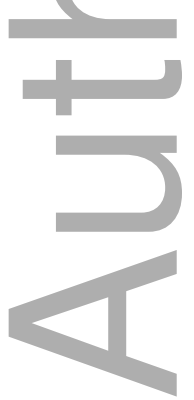




\section{University Library}

\section{- M M N E R VA A gateway to Melbourne's research publications}

Minerva Access is the Institutional Repository of The University of Melbourne

Author/s:

Kaur, $\mathrm{P}$

Title:

Hair-follicle dermal papilla and sheath fibroblasts provide a supportive microenvironment for human skin regeneration.

Date:

2017-05

Citation:

Kaur, P. (2017). Hair-follicle dermal papilla and sheath fibroblasts provide a supportive microenvironment for human skin regeneration.. Br J Dermatol, 176 (5), pp.1123-1124. https://doi.org/10.1111/bjd.15474.

Persistent Link:

http://hdl.handle.net/11343/292833 